V.A. Lebedev

\title{
ON THE SOLUTION OF THE PROBLEM OF SYNTHESIS OF THE CONTROL SYSTEM FOR THE PROCESS OF DOSED FEED OF ELECTRODE WIRE FOR ARC WELDING EQUIPMENT
}

\begin{abstract}
Goal. Refinement of the methodology for the development of an effective control system for an electric drive with controlled relaytype regulators for organizing a metered feed of an electrode wire using the parameters of the arc process with the possibility of using it in design practice and practice of technological application. Methodology. The proposed method for the mathematical description (mathematical model) of the system of the developed structure electric drive - arc process with current feedback of welding with a variable structure device is based on the theory of automatic control as applied to nonlinear elements, the application of the theory of operational calculus. At the same time, a selection and description of a nonlinear node in the feedback circuit in the form of a relay element with a certain structure and subsequent linearization of this element was made. As an electric motor of the electrode wire feeder, a new development of a specialized valve electric motor is used, which is used in the system with a microprocessor controller. Results. Due to the presence of a substantially nonlinear link, the calculation of the valve electric drive system - the arc process can be found on the basis of a system of nonlinear differential equations, which is practically impossible for practical application. In this work, these complications are overcome on the basis of a rational choice of the description of the nonlinear link, its harmonic linearization and obtaining on this basis a mathematical description of the system, from which, using the methodology of operational calculus, the relations necessary for calculating the parameters of the system are determined in analytical form. Originality. The problem of calculating a rather complex problem of mathematical description of the valve electric drive system - a technological link in the form of an arc process with a substantially nonlinear link in the feedback circuit in the work is solved with the effective use of a set of methodological methods, which include as a means of representing individual links, including nonlinear links selected simplifications and solutions of the obtained differential equations using original methods of operational calculus. The proposed method (mathematical model) is tested in two directions - oscillography of a real system, as well as system simulation. Practical significance. Using the developed methods for describing the control system, it is possible to calculate its characteristics and, on their basis, select the parameters for setting the electric drive controller, which allows, without additional experimental research, to obtain the necessary character of the transfer of electrode metal, and, consequently, the quality of the result of the arc process. References 12, figures 4.
\end{abstract}

Key words: welding process, electrode wire, pulse feed, control system, mathematical description, calculation.

Проаналізовано існуючі системи активного впливу на перенесення електродного металу при управлінні процесом дугового зварювання плавким електродом, в тому числі, і на основі імпульсної подачі електродного дроту. Особливо виділено новий спосіб зварювання - з керованими параметрами руху за рахунок введення в електропривод зворотних зв'язків за параметрами дугового процесу зварювання-наплавлення з дозованою подачею дроту. Розглянуто алгоритм реалізації зварювання з дозованою подачею. Обрано електропривод механізму подачі, який базується на спеціально розробленому швидкодіючому вентильному електродвигуні з комп'ютеризованим регулюванням. Для аналізу $і$ вибору параметрів иієї системи запропоновано розглядати ї̈ в комплексі з дуговим процесом із застосуванням методів гармонійної лінеаризації. Бібл. 12, рис. 4.

Ключові слова: зварювальний процес, електродний дріт, імпульсна подача, система управління, математичний опис, розрахунок.

Проанализированы существуюшие системы активного влияния на перенос электродного металла при управлении прочессом электродуговой сварки плавящимся электродом, в том числе, и на основе импульсной подачи электродной проволоки. Особо выделен новый способ сварки - с управляемыми параметрами движения за счёт введения в электропривод обратных связей по параметрам дугового прочесса свврки-наплавки с дозированной подачей проволоки. Рассмотрен алгоритм реализачии сварки с дозированной подачей. Выбран электропривод механизма подачи, который базируется на специально разработанном быстродействующем вентильном электродвигателе с компьютеризованным регулированием. Для анализа и выбора параметров этой системы предложено рассматривать её в комплексе с дуговым процессом с применением методов гармонической линеаризации. Библ. 12, рис. 4.

Ключевые слова: сварочный процесс, электродная проволока, импульсная подача, система управления, математическое описание, расчёт.

Introduction. Arc mechanized and automatic welding and consumable electrode surfacing is one of the most common technological processes with a wide range of applications and it is predicted that it will continue to develop in the future, improving in all directions and areas of application. The widespread use of mechanized arc welding using both solid and flux-cored electrode wires determines the search for new technical solutions

aimed at improving the process technology, as well as updating the park of mechanized and automatic equipment with new technical capabilities [1].

The main directions in improving the technology of welding and surfacing and the corresponding types of equipment are associated with the use of pulse algorithms for the functioning of automatic and semi-automatic

(C) V.A. Lebedev 
systems [2]. Recently, the technical and technological improvement of automatic and semi-automatic devices is associated with the development and designing of one of the main systems - an electrode wire feed system with a basic unit - a feed mechanism. The main developments in this direction are associated with the use of a pulse feed of an electrode wire. There are developments of both simple systems with practically no regulation of pulse parameters, and with sufficiently perfect mechanisms, and this is described in detail in [3]. It can be noted that the use of a modern feed mechanism providing pulse motion of the electrode wire allows, with correctly selected parameters, to control the transfer of electrode metal drops, which in turn allows (mainly) $[4,5]$ :

- to significantly reduce the loss of electrode metal for waste and splashing;

- to change the geometrical dimensions of the weld and weld bead, as well as the heat-affected zone;

- to influence the structure of the weld metal, improving its operational properties (strength, wear resistance, including corrosion, etc.);

- to reduce energy costs for conducting welding and surfacing processes.

Additionally, it should be noted the low value of the inertia of the electric motor.

The improvement of the electrode wire feed system is developed using the achievements of the element base and technical solutions based on them. The latest developments of mechanisms with pulse algorithms of functioning are based on the use of gearless electric drives with brushless valve and stepper motors with microprocessor control of the rotation frequency of their shafts, and, consequently, the movement of the electrode wire with high speed levels. Such systems are constantly being improved in different directions and in different systems of automatic welding and surfacing equipment. One of them develops quite intensively in the electrode wire feed system and is associated with the introduction of feedbacks into the electric drive regulator according to the parameters of the arc process - either current or voltage. This solution made it possible to implement a new type of arc process - welding-surfacing with a dosed feed of the electrode wire [6].

The goal of the work is the refinement of the methodology for the development (synthesis) of an effective control system for an electric drive with controlled relay-type regulators for organizing a dosed feed of electrode wire using the parameters of the arc process with the possibility of using it in design practice and practice of technological application.

Statement of the problem. Figure 1 schematically shows the formation of feedback on the arc process. In this case - by the welding current in the process with short circuits of the arc gap at the moments of switching on and off the drive of the electrode wire feed, depending on the desired (required) results of technological processes of welding and surfacing. Switching times on the graph in Fig. 1 marked with points $\left\langle c »\left(I_{w \min }\right)\right.$ and $« b »\left(I_{w \max }\right)$.

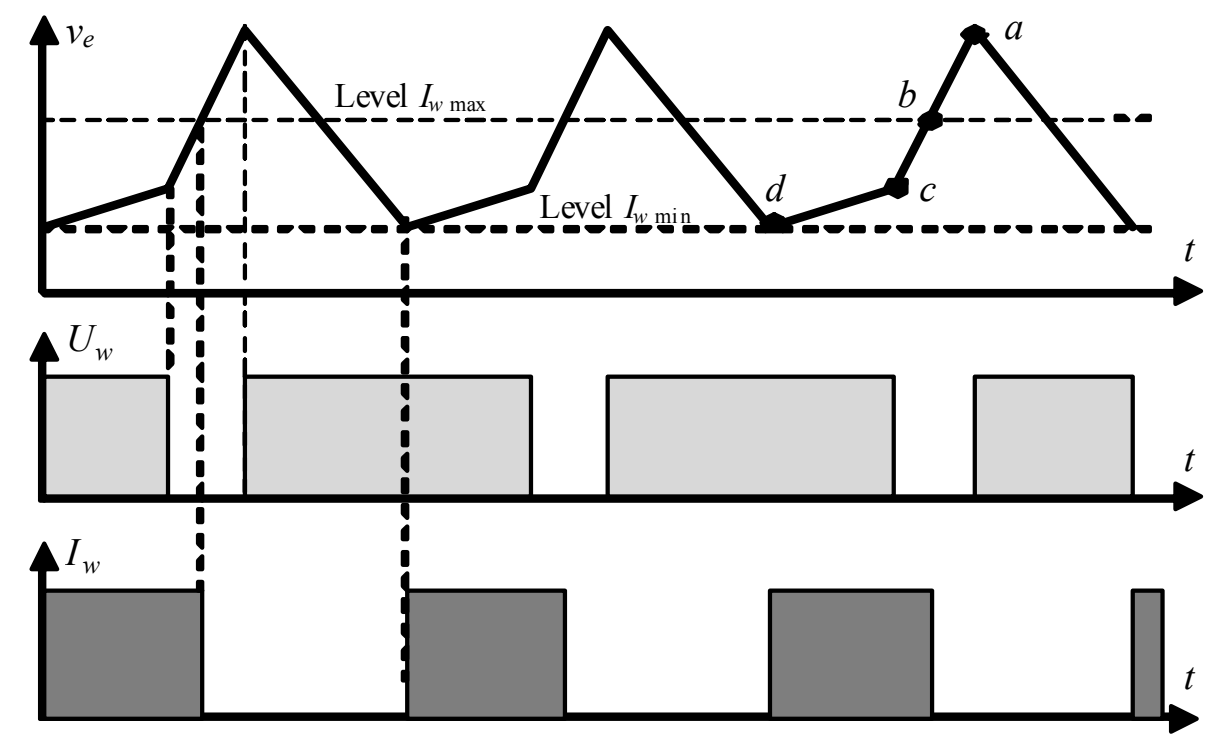

Fig. 1. The operation algorithm of the electrode metal transfer control system associated with the parameters of the arc process current: $I_{w}$ - welding current; $U_{w}$ - welding voltage; $v_{e}$ - feed speed of the electrode wire; $a$ - transition of the drop into the bath; $b$ - pause in feed rate; $c, d$ - start of feeding

For synchronization (coincidence) of mechanical pulses (feed pulses) with the frequency of short circuits of the arc gap, information feedback on the parameters of the arc is introduced into the control system so that a pause in the supply always begins after a short circuit.
It should be noted that informational feedback on the arc process current is more effective than voltage feedback due to the fact that arc power sources used in the welding-surfacing process, having, as a rule, rigid external volt-ampere characteristics, are less sensitive to 
the voltage of the welding process in the feedback. Conditions may exist where voltage feedback will take priority.

Feedback makes it possible to automatically selfadjust the electric drive of the feed mechanism according to the parameters corresponding to the natural (physical) nature of the welding arc and, which eliminates the timeconsuming choice of frequency and duty cycle of mechanical pulses, the parameters of which are very difficult to predetermine.
Figure 2 schematically shows the system of dosed control of the arc welding process with short circuits of the arc gap, including the main links of the system with transmission elements: $W_{d}-$ valve motor; $W_{s}-$ arc welding process; $W_{r}$ - electric drive regulator; $W_{n l}-$ nonlinear link that determines the moments of switching the welding current at the minimum $i_{w \text { min }}$ and maximum $i_{w \max }$ currents of the welding process.

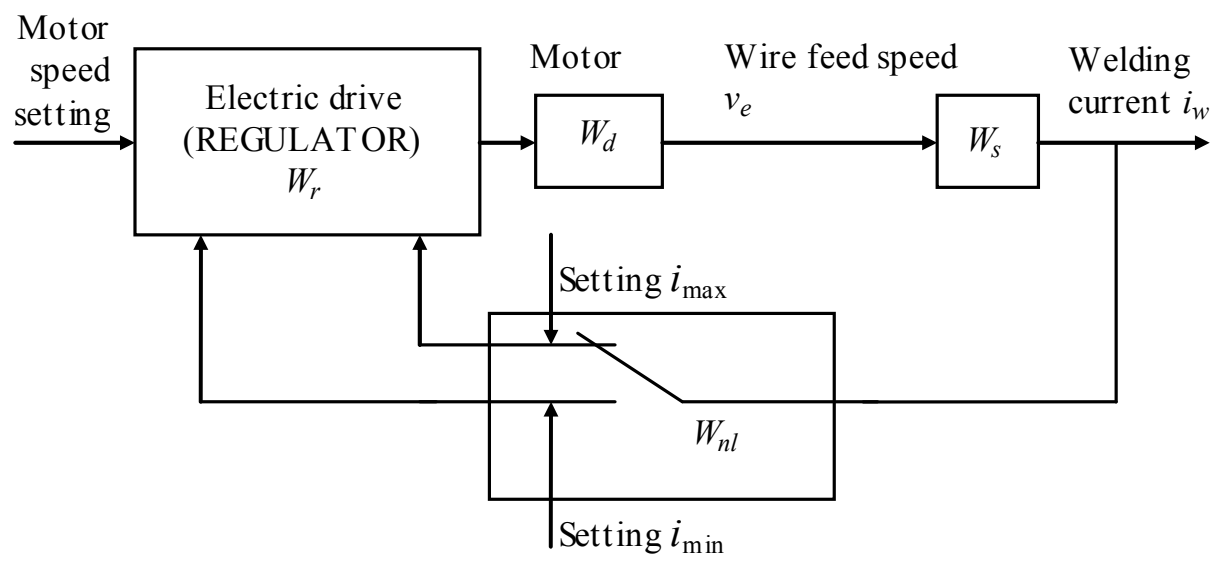

Fig. 2. Block diagram of the control system of the welding process with dosed wire feed with non-linear switching link

The expressions for determining the gear ratios of the links are defined as follows.

It is known that the transfer function of a valve motor in operator form can be identified with the transfer function of a DC motor [7] and written in a somewhat simplified form

$$
W_{d}(p)=\frac{\omega(p)}{U(p)}=\frac{K}{T_{m} p+1},
$$

where $\omega$ is the shaft rotation frequency; $U$ is the supply voltage; $K$ is the value inversely proportional to the constructive constant of the electric motor; $T_{m}$ is the electromechanical constant of the phase of the electric motor, taking into account the inertial characteristics of the gearless feed mechanism (rollers).

For the transfer function of the link describing in the operator form the arc welding process with short circuits of the arc gap, an expression is proposed that we obtained in [8].

$$
W_{n l}(p)=\frac{i_{w}(p)}{\omega(p)} \cdot \frac{\frac{E}{R+0,5 \cdot b}}{T \cdot p^{2}+p+k}
$$

or

$$
W_{n l}(p)=\frac{i_{w}(p)}{\omega(p)} \cdot \frac{S}{T_{1}^{2} \cdot p^{2}+p+k},
$$

where

$$
T=\frac{L}{R+0,5 \cdot b_{1}} ; \quad k=\frac{A \cdot H \cdot E}{R+0,5 \cdot b_{1}},
$$

in turn $L, R$ are the inductance and equivalent resistance of the welding circuit, respectively; $b_{1}$ is the coefficient characterizing the slope of the static characteristics of the arc to the current axis; $E$ is the electric field strength in the arc column;

$$
A=\frac{1}{M \cdot \pi \cdot r^{2}} ; \quad H=U_{i}(0,285-0,0052 \cdot U),
$$

where $U_{i}$ is the open circuit voltage of the welding power source; $M$ is the coefficient determining the thermal state of the electrode metal

$$
M=C_{n} \cdot \gamma_{n} \cdot T_{n}-C_{o} \cdot \gamma_{o} \cdot T_{o}+r_{n} \cdot \gamma_{o},
$$

where $C_{n}, C_{o}$ is the heat capacity of the metal at melting and ambient temperatures, respectively; $\gamma_{n}, \gamma_{o}$ is the density of the metal at melting and ambient temperatures, respectively; $r_{n}$ is the latent heat of fusion; $T_{n}, T_{o}$ are the melting temperature of the electrode metal and the ambient temperature, respectively;

$$
S=\frac{E}{R+0,5 b_{1}} .
$$

Usually, for an electric drive regulator providing additional control qualities (minimum overshoot, minimum possible time for changing the frequency of rotation of the electric motor shaft in transients, etc.), various structures are used, for example, PI regulators, relay current regulators, etc. In our case, to simplify consideration of the dosed control system without prejudice to the essence of the analysis, we take the regulator transfer function in the operator representation in the following form

$$
W_{p}(p)=\frac{U_{s v}(p)}{U(p)}=\frac{K_{p}}{T_{p} \cdot p+1},
$$


where $U_{s v}$ is the supply voltage; $K_{p}$ is the regulator gain; $T_{p}$ is the controller time constant.

The description of the transfer function of a nonlinear link providing switching of voltage levels proportional to the current of the welding process presents some difficulties, in particular, because the nonlinearity has an asymmetric nature.

Several options for analyzing such a nonlinear system can be proposed. The simplest and most effective option may be using mathematical modelling. However, such a solution is not always possible for use in design and especially technological practice when choosing the parameters of the nonlinear link in the feedback circuit that determine the characteristics of the transfer of electrode metal drops.

Presentation of the main material. In the system under consideration, by switching, the connections between the elements change depending on its state, therefore, such a system can be fully attributed to a system with a variable structure [9]. The structural diagram of such a system changes during the transient in such a way as to ensure the high-quality performance of control tasks for the welding process by influencing the transfer of electrode metal drops. A serious obstacle to the use of analytical methods and computational tools for the construction of effective control algorithms for modern technical objects, which include arc welding processes, including with doses feed, is a wide range of their characteristics, both in the composition of the system components and in the effects. A promising method in solving problems of describing systems with variable structure can be the use of techniques for analyzing sliding modes. However, the obvious complexity of obtaining analytical expressions for this method of studying a system with a variable structure also cannot be applied both in design and in technological practice.

The two above-mentioned methods of analyzing a system with a nonlinear element are quite accurate, but obviously difficult for application. It is necessary to consider approximate methods of obtaining the mathematical description of nonlinear links [10, 11]. A number of these methods are discussed in the monograph [12]. It seems to us that the harmonic balance method will be the most acceptable for the considered control system.

Figure 3 in a formalized form shows a nonlinear asymmetric relay element corresponding to the $W_{n l}$ link in Fig. 2.

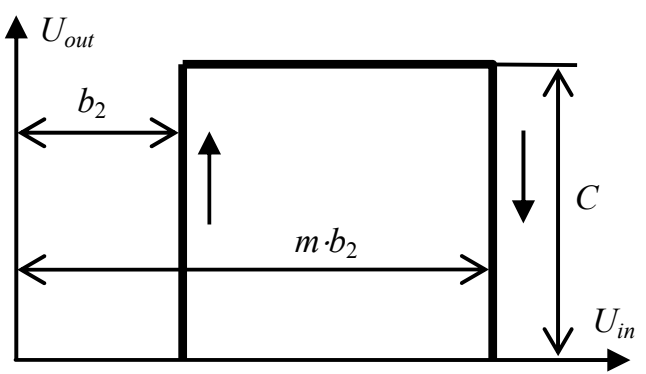

Fig. 3. Formalized representation of a relay asymmetric link (designation in the text)
Obviously, nonlinearity is ambiguous, which should be reflected in the transfer function of the nonlinear link.

The transfer function of the nonlinear link in Fig. 3 consists of an equivalent complex transfer coefficient, which includes a constant component $F^{0}$ and harmonic linearization coefficients $q$ and $q^{\prime}$

$$
W_{n l}=F^{0}\left(A, x^{0}\right)+q\left(A, x^{0}\right)+q^{\prime}(A),
$$

where $F^{0}$ is the constant component; $A, x^{0}$ are the amplitude and displacement of the center of oscillations, which, according to [10], can be defined as

$$
F^{0}\left(A, x^{0}\right)=\frac{c}{2}-\frac{c}{2 \pi}\left(\arcsin \frac{b_{2}-x^{0}}{A}+\arcsin \frac{m \cdot b_{2}-x^{0}}{A}\right) ;
$$

At

$$
A \geq\left|b_{2}-x^{0}\right|, \quad A \geq\left|x^{0}-m \cdot b_{2}\right|
$$

where $c, b, m$ are the maximum value of the relay pulse; the period in which the pulse is switched off; the part of the period at which the pulse turns on, respectively

$$
q\left(A, x^{0}\right)=\frac{c}{\pi A}\left[\sqrt{1-\frac{\left(b_{2}-x^{0}\right)^{2}}{A^{2}}}+\sqrt{1-\frac{\left(m \cdot b_{2}-x^{0}\right)^{2}}{A^{2}}}\right],(6)
$$

at

$$
\begin{gathered}
A \geq\left|b_{2}-x^{0}\right|, \quad A \geq\left|x^{0}-m \cdot b_{2}\right|, \\
q^{\prime}(A)=-\frac{c \cdot b_{2}}{\pi \cdot A}(1-m),
\end{gathered}
$$

at

$$
A \geq\left|b_{2}-x^{0}\right|, \quad A \geq\left|x^{0}-m \cdot b_{2}\right|
$$

Taking into account (4)-(7), as well as using simple algebraic transformations, we obtain an approximate linear dependence of the output variable of the nonlinear link on its input variable: with the transfer function

$$
\begin{aligned}
& W_{n l}(p)=c\left\{\frac{1}{2}-\frac{1}{2 \cdot \pi}\left(\arcsin \frac{b_{2}-x^{0}}{A}+\arcsin \frac{m \cdot b_{2}-x^{0}}{A}\right)+\right. \\
& +\frac{1}{\pi \cdot A}\left[\sqrt{1-\frac{\left(b_{2}-x^{0}\right)^{2}}{A^{2}}}+\sqrt{1-\frac{\left(m \cdot b_{2}-x^{0}\right)^{2}}{A^{2}}}\right]- \\
& \left.--\frac{b_{2} \cdot p}{\pi \cdot \omega \cdot A}(1-m)\right\} .
\end{aligned}
$$

Thus, under the influence of harmonic vibrations, the nonlinear link seems to be linearized and can be considered approximately as a linear link. The coefficients $q$ and $q^{\prime}$ indicated above can be called harmonic gains of the nonlinear link. It can be seen from the formulas for the coefficients that $F^{0}, q$ and $q^{\prime}$ depend on the amplitude of the input signal. This dependence reflects the nonlinear properties of the link and because of it, the superposition principle is inapplicable for a harmonically linearized nonlinear link.

The transfer function of the closed-loop control system of the arc welding process with a dosed feed of the 
electrode wire can be written as an equation in operator form as follows:

$$
\frac{i(p)}{U_{v t}(p)}=\frac{W_{p}(p) \cdot W_{d}(p) \cdot W_{w}(p)}{1+W_{p}(p) \cdot W_{d}(p) \cdot W_{w}(p) \cdot W_{n l}(p)},
$$

where $U_{v t}$ is the setting voltage.

Let us introduce the notation

$$
\begin{gathered}
D=c\left\{\frac{1}{2}-\frac{1}{2 \pi}\left(\arcsin \frac{b_{2}-x^{0}}{A}+\arcsin \frac{m b_{2}-x^{0}}{A}\right)+\right. \\
\left.+\frac{1}{\pi A}\left[\sqrt{1-\frac{\left(b_{2}-x^{0}\right)^{2}}{A^{2}}}+\sqrt{1-\frac{\left(m b_{2}-x^{0}\right)^{2}}{A^{2}}}\right]\right\} ; \\
N=-\frac{b_{2}}{\pi \cdot \omega \cdot A}(1-m) .
\end{gathered}
$$

Taking into account (1)-(3), (9)-(11), we obtain a complete expression for determining the desired dependence $\frac{i(p)}{U_{v t}(p)}$ in the operator form:

$$
\begin{aligned}
& \frac{i(p)}{U_{v t}(p)}= \\
& =\frac{K_{p} \cdot K_{d} \cdot S}{\left(T_{p} \cdot p+1\right) \cdot\left(T_{d} \cdot p+1\right) \cdot\left(T_{1}^{2} \cdot p^{2}+T_{2} \cdot p+k\right)+K_{p} \cdot K_{d} \cdot S(D-N \cdot p)}
\end{aligned}
$$

The solution of the operator equation (12) in the form of obtaining the analytical dependence $i=f\left(U_{v t}\right)$ presents certain difficulties, including because of the high order of $p$. Such a possibility is presented when using machine research methods and using mathematical modelling.

Modern mathematics does not allow solve equations in general form above the third order by simple methods, so we will look for ways to lower the order of the unknown $p$ whose maximum order is $p^{4}$.

Several engineering calculation methods are used to study a linearized link system. First of all, take into account that the time constant of the regulator is very small and the transfer function of the link (3) can be excluded or included in the transfer function with the gain that is taken into account by the link (1). Taking this into account, equation (12) can be rewritten in a simplified form

$$
\begin{aligned}
& \frac{i(p)}{U_{v t}(p)}= \\
& =\frac{K_{d} \cdot S}{T_{d} \cdot T_{1}^{2} \cdot p^{3}+\left(T_{1}^{2}+T_{d} \cdot T_{2}\right) \cdot p^{2}+\left(T_{d} \cdot k+T_{2}\right) \cdot p+k+K_{d} \cdot S(D-N \cdot p)} .
\end{aligned}
$$

We will study the linearized equation (13) using one of the engineering methods - the frequency method of E.P. Popov.

From expression (13) we determine the characteristic equation

$$
\begin{aligned}
& T_{d} \cdot T_{1}^{2} \cdot p^{3}+\left(T_{1}^{2}+T_{d} \cdot T_{2}\right) \cdot p^{2}+ \\
& +\left(T_{d} \cdot k+T_{2}\right) \cdot p+k+K_{d} \cdot S(D-N \cdot p)=0 .
\end{aligned}
$$

Let us divide equation (14) into the real and imaginary parts by substituting $p=j \cdot \omega$ as shown below

$$
\left(k+K_{d} \cdot S \cdot D-\left(T_{1}^{2}+T_{d} \cdot T_{2}\right) \cdot \omega^{2}=0 ;\right.
$$

$$
\left(T_{d} \cdot k+T_{2}+K_{d} \cdot S \cdot N\right) \cdot \omega+k-T_{d} \cdot T_{1}^{2} \cdot \omega^{2}=0 .
$$

The frequency of the periodic process $\omega$ is determined by solving the quadratic equation (16). The discriminant of equation (16)

$$
\left(T_{d} \cdot k+T_{2}+K_{d} \cdot S \cdot N\right)^{2}-4 \cdot T_{d} \cdot T_{1}^{2} \cdot k=0 .
$$

An important conclusion follows from expression (17) that self-oscillations with frequency $\omega$ can take place under the condition

$$
\left(T_{d} \cdot k+T_{2}+K_{d} \cdot S \cdot N\right)^{2} \geq 4 \cdot T_{d} \cdot T_{1}^{2} \cdot k .
$$

Having determined the frequency $\omega$ from equation (15) and substituted it into equation (15), one can also determine the amplitude of self-oscillations.

Since, among other things, the frequency and amplitude of self-oscillations are determined by the values of $b_{2}$ and $m \cdot b_{2}$, which practically corresponds to the minimum $i_{w \text { min }}$ and the maximum $i_{w \text { max }}$ values of the current of the arc process, which in turn determines the nature of the transfer of the electrode metal, which determines the results of welding with the use of a dosed feed of the electrode wire.

Checking the obtained results. The evaluation and reliability of the results obtained were carried out by comparing the oscillograms of the arc process current with the results obtained in mathematical modelling with the same initial data.

Figure 4 shows several options for presenting currents and voltages for mechanized electric arc welding in a protective gas environment when feeding the electrode wire in the usual way (Fig. 4,a) and using the algorithms for dosed feed (Fig. 4,b).

Comparison of real oscillograms of current and voltage with data obtained by computer simulation using the MATLAB (Simulink) environment (Fig. 4,c) indicate a fairly close result in frequency of the transfer of electrode metal.

A coincidence was obtained within 10-15\% and this is an acceptable result for the technologies of mechanized and automatic welding processes - surfacing with pulse algorithms for feeding the electrode wire and confirming the efficiency of the proposed method.

The proposed method for calculating the operating parameters of an electric drive in the system of technical implementation of the welding and surfacing method with a dosed feed of the electrode wire based on the introduction of an adjustable feedback on the arc process current has a very important practical application and makes it possible to determine the combination of the minimum $i_{w \text { min }}$ and maximum $i_{w \text { max }}$ values of the welding process current which determine the frequency and amplitude of the arc current pulses and, as a result, the controlled frequency of transfer of the electrode metal drops and thereby provide the quality indicators of the resulting welds and deposited layers (spattering, heat input, formation, penetration, electricity consumption, etc.). Experimentally, it is rather difficult to select the parameters of the feedback settings, since in practice various types and diameters of the electrode wire are used, different process modes are used, etc. 

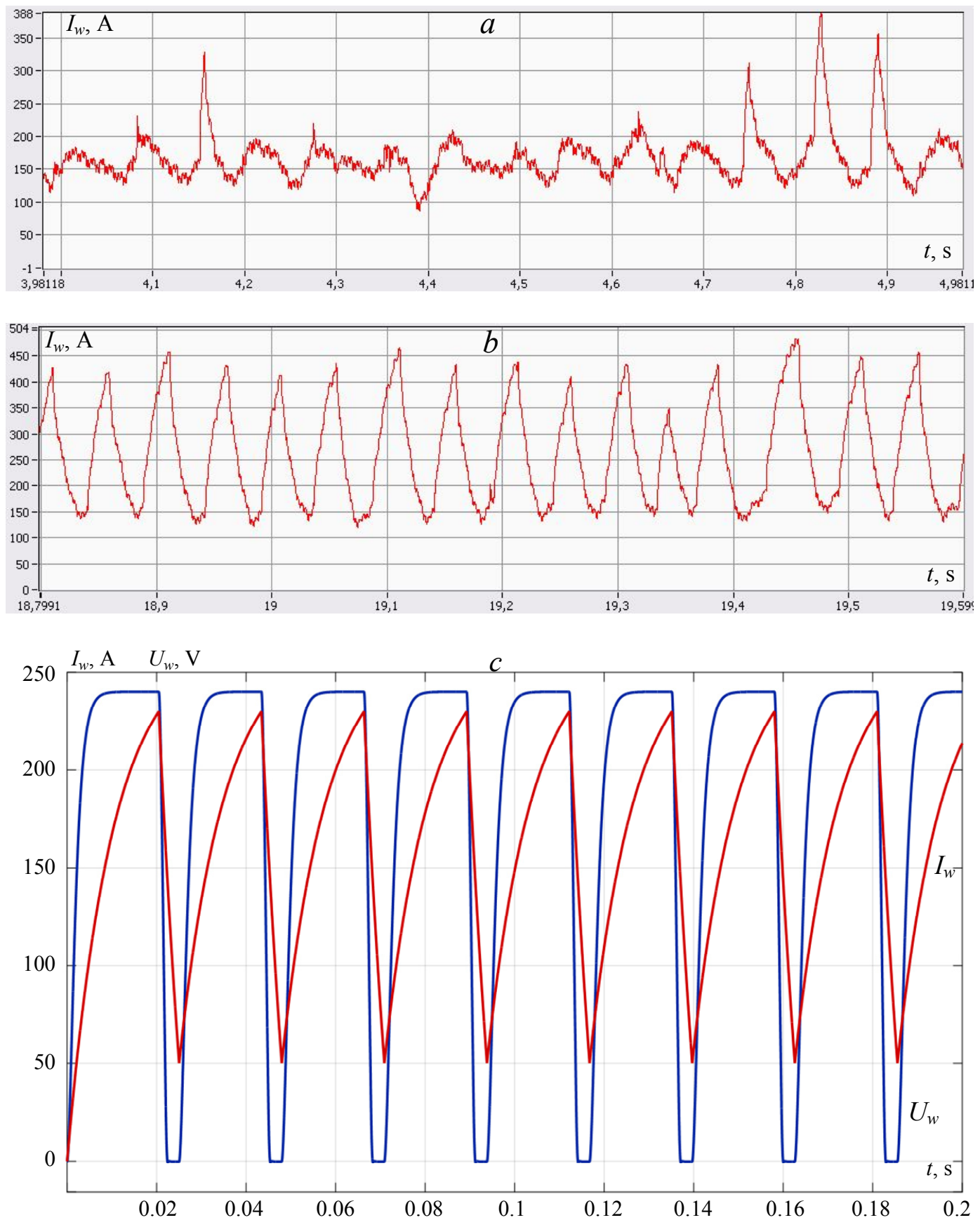

Fig. 4. Comparative results of the study of the arc welding and surfacing process: $a$-current of the conventional process; $b$-current of the process with dosed electrode wire feed; $c$-modelling of the welding process (qualitative representation)

\section{Conclusions.}

1. The control system for the arc welding process with a dosed pulse feed of the electrode wire, which includes a mathematical representation of the welding process, contains a substantially nonlinear link in the arc process current feedback loop, which can be linearized to study the system. In this case, for the problems of choosing the parameters for controlling the transfer of electrode metal, the method of harmonic linearization is most applicable, in which a nonlinear element can be represented by an asymmetric relay link.

2. The study of the developed control system can most expediently be carried out using the methods of operational calculus, the use of which makes it possible to obtain results applicable in design and technological practice, and determining the results of the arc process.

3. Verification of the applied research methods of the developed control system of the welding process with the use of a dosed feed of the electrode wire carried out using computer simulation and obtaining characteristic oscillograms confirms the adequacy of the selected research methods.

Conflicts of interests. The authors declare no conflict of interest.

\section{REFERENCES}

1. Paton B.E. Welding problems at the turn of the century. Automatic welding, 1999, no. 1, pp. 4-14. (Rus). 
2. Harris I. Transfer of heat and mass to the base metal in gas metal arc welding. Welding, Brazing, and Soldering, 2011, vol. 6, pp. 82-88.

3. Paton B.E., Lebedev V.A., Pichak V.G., Poloskov S.Yu. The evolution of pulsed wire feed systems for welding and surfacing. Welding and Diagnostics, 2009, no. 3, pp. 46-51. (Rus).

4. Zhao Y., Lee P.-S., Chung H. Effect of pulsing parameters on drop transfer dynamics and heat transfer behavior in pulsed gas metal arc welding. International Journal of Heat and Mass Transfer, 2019, vol. 129, pp. 1110-1122. doi: https://doi.org/10.1016/j.ijheatmasstransfer.2018.10.037.

5. Nadzam J. Tandem GMAW: The Flexibility of Pulsed Spray Transfer. Welding Innovation, 2002, vol. 19, no. 2, pp. 18-21.

6. Lebedev V.A., Zhuk G.V. Transferal control of electrode metal on the basis of pulsed-type algorithms of system operation with dosing activity of continuous electrode by mechanized arc welding. Heavy Engineering, 2017, no. 6, pp. 27-32. (Rus).

7. Lebedev V.A., Guly M.V. The high-speed valve electric drive for the equipment of the mechanized arc welding. Mechatronics, automation, control, 2014, no. 6. pp. 47-51. (Rus).

8. Lebedev V.A. Povyshenie effektivnosti svarochnogo oborudovaniia na osnove issledovaniia impul'snykh vozdeistvii v sisteme podachi elektrodnoi provoloki. Diss. dokt. techn. nauk [Increasing the efficiency of welding equipment based on the study of impulse effects in the electrode wire feed system. Doc. tech. sci. diss.]. Kyiv, 2010. (Rus).

How to cite this article:

Lebedev V.A. On the solution of the problem of synthesis of the control system for the process of dosed feed of electrode wire for arc welding equipment. Electrical Engineering \& Electromechanics, 2021, no. 1, pp. 20-26. doi: 10.20998/2074-272X.2021.1.04.
9. Emelyanov S.V. Teoriya sistem s peremennoj strukturoj [Theory of systems with variable structure]. Moscow, Science Publ. House, 1970. 592 p. (Rus).

10. Abu-Khalaf M., Huang J., Lewis F.L. Nonlinear H2/HInfinity Constrained Feedback. Control Springler, 2006. 203 p.

11. Agachi P.S., Cristea M.V., Csavdari A.A., Szilagyi B. Advanced process engineering control. Walter de Gruyter GmbH, Berlin, Germany, 2017. 412 p.

12. Besekersky V.A., Popov E.P. Teoriya sistem avtomaticheskogo regulirovaniya [Theory of automatic control systems]. Moscow, Science Publ. House, 1975. 768 p. (Rus).

Received 04.09.2020

Published 25.02.2021

V.A. Lebedev, Doctor of Technical Science, Professor, SF «Experimental Design-Technological Office of the E.O. Paton Electric Welding Institute of the National Academy of Sciences of Ukraine», 7, Bogenko Str., Kiev, 03150, Ukraine, e-mail: valpaton@ukr.net
Accepted 10.11.2020 